\title{
A national two year follow up study of extremely low birthweight infants born in 1996-1997
}

\author{
V Tommiska, K Heinonen, P Kero, M-L Pokela, O Tammela, A-L Järvenpää, \\ T Salokorpi, $M$ Virtanen, $V$ Fellman
}

Arch Dis Child Fetal Neonatal Ed 2003;88:F29-F35

See end of article for authors' affiliations

Correspondence to:

Dr Fellman, Hospital for Children and Adolescents, University of Helsinki,

Stenbäckinkatu 11 ,

000290 Helsinki, Finland;

Vineta.Fellman@hus.fi

Accepted 22 May 2002

\begin{abstract}
Objective: To study neurodevelopmental outcome in a two year cohort of extremely low birthweight (ELBW) infants at 18 months corrected age, to compare the development of the ELBW infant subcohort with that of control children, and to find risk factors associated with unfavourable outcome.

Study design: All 211 surviving ELBW infants (birth weight < $1000 \mathrm{~g}$ ) born in Finland in 1996-1997 were included in a national survey. The ELBW infants $(n=78)$ who were born and followed in Helsinki University Hospital belonged to a regional subcohort and were compared with a control group of 75 full term infants. A national follow up programme included neurological, speech, vision, and hearing assessments at 18 months of corrected age. Bayley infant scale assessment was performed on the subcohort and their controls at 24 months of age. Risk factors for unfavourable outcome were estimated using logistic and linear regression models.

Results: The prevalence of cerebral palsy was $11 \%$, of all motor impairments $24 \%$, of ophthalmic abnormalities $23 \%$, and of speech delay $42 \%$. No impairment was found in $42 \%$ of children, and $18 \%$ were classified as severely impaired. The prevalence of ophthalmic abnormalities decreased with increasing birth weight and gestational age, but the prevalence of other impairments did not. In the subcohort, a positive correlation was found between the date of birth and Bayley scores.

Conclusion: Ophthalmic abnormalities decreased with increasing birth weight and gestational age, but no other outcome differences were found between birthweight groups or in surviving ELBW infants born at 22-26 weeks gestation. The prognosis in the regional subcohort seemed to improve during the short study period, but this needs to be confirmed.
\end{abstract}

A dvances in prenatal and neonatal care during the last few decades have made it possible for infants born extremely prematurely to survive. Concerns have been expressed about the long term outcome of these infants. In recent follow up surveys, the neurodevelopmental impairment rate of low birthweight infants has not changed significantly, ${ }^{1-4}$ and the disability rate of the most immature infants has remained considerable. ${ }^{56}$ However, rapid progress in obstetric and neonatal care quickly makes outcome results out of date. Also concerns about the increasing costs and the ethics of caring for extremely low birthweight (ELBW) infants have prompted a continuous long term outcome evaluation of recently born cohorts.

Most surveys are based on neonatal intensive care units and give good regional reference, but more generally applicable results can only be drawn from population based studies. In addition, comprehensive data collection is essential for reliable results. It has been shown that generalisation can suffer if only those followed with ease are included. ${ }^{7}$ For this reason, we established a national ELBW infant register including prospectively all ELBW infants born in Finland from 1 January 1996, and we collected information on these infants from the perinatal period to 18 months of age corrected for prematurity. Our aims were to obtain comprehensive data on ophthalmic outcome at 12 months of corrected age and neurodevelopmental outcome at 18 months of corrected age in a two year cohort of ELBW children, to compare the mental development of a subcohort of ELBW infants with that of full term controls at 24 months of corrected age, and to detect risk factors associated with unfavourable outcome.

\section{SUBJECTS \\ National cohort}

The national study population consisted of all infants with a birth weight below $1000 \mathrm{~g}$ and gestational age at least 22 full weeks born in Finland during a two year period from 1 January 1996 to 31 December $1997 .{ }^{8}$ Of the 529 ELBW infants (0.4\% of all 121330 infants born in Finland 1996-1997), 178 (34\%) were stillborn and 351 (66\%) liveborn. The neonatal survival rate was $62 \% ; 211(60 \%)$ ELBW infants survived until the age corresponding to 40 weeks gestation. ${ }^{8}$

\section{Regional subcohort and controls}

One third of the liveborn ELBW infants were born and treated in Helsinki University Hospital, serving a geographically defined region with neonatal intensive care, and formed the subcohort of the study. Of the 109 liveborn infants, 86 (79\%) were alive at the age corresponding to 40 weeks gestation, and 78 had a neuropsychological assessment in the same hospital at the corrected age of 24 months. Of the remaining eight infants not screened at 24 months of age, two had died and six families lived outside the Helsinki region.

Full term infants born immediately after each ELBW infant in the same hospital (in 1996 one infant, in 1997 the next two infants) were eligible for the control group. The inclusion criteria for control infants were: gestational age $\geqslant 37$ weeks; no requirement for medical care during the first three days; native language of parents Finnish, Swedish, or English. Four infants were excluded: two families had moved a long way from Helsinki, and in two cases the children did not live with their parents. A total of 75 of the 126 invited controls (60\%) were entered into the study. 
Table 1 Birth characteristics of all surviving extremely low birthweight (ELBW) infants, the subcohort (ELBW infants born and followed in Helsinki University Hospital), and their controls

\begin{tabular}{|c|c|c|c|}
\hline & $\begin{array}{l}\text { All surviving ELBW infants } \\
\text { (208 infants, } 193 \text { mothers) }\end{array}$ & $\begin{array}{l}\text { Subcohort (78 infants, } 74 \\
\text { mothers) }\end{array}$ & $\begin{array}{l}\text { Control group ( } 75 \text { infants, } \\
75 \text { mothers) }\end{array}$ \\
\hline \multicolumn{4}{|l|}{ Basic data } \\
\hline Primiparity & $104(54)$ & $42(58) \dagger$ & $26(35)$ \\
\hline Unmarried mother & $67(37)$ & $31(42) \dagger$ & $16(21)$ \\
\hline Upper social classes 1-2 & $120(65)$ & $47(64) \dagger$ & 62 (83) \\
\hline Lower social classes 3-4 & $66(36)$ & $27(36) \dagger$ & 13 (17) \\
\hline Mother smoked & 37 (19) & $14(19)$ & $9(12)$ \\
\hline Mother's age (years) & $31.5(16.3-48.5)$ & $32.5(21.5-47.5)$ & $32.0(21.3-43.9)$ \\
\hline Birth weight $(g)$ & 807 (447-995) & 778 (447-995)†* & 3671 (2530-5250) \\
\hline Gestational age (weeks) & $27.3(22.3-34.9)$ & $27.1(23.7-32.6) \dagger$ & $39.9(37.3-42.1)$ \\
\hline Male sex & $97(47)$ & $38(49)$ & $39(52)$ \\
\hline Multiple pregnancy & 55 (26) & $16(21) \dagger$ & $2(3)$ \\
\hline Antenatal steroid treatment & $164(79)$ & $69(88) \dagger^{*}$ & 0 \\
\hline Born in tertiary hospital & $187(90)$ & $78(100)$ & 75 (100) \\
\hline Vaginal delivery & $68(33)$ & $23(29) \dagger$ & 58 (77) \\
\hline \multicolumn{4}{|l|}{ Morbidity data } \\
\hline Small for gestational age & $84(40)$ & $35(45) \dagger$ & $1(1)$ \\
\hline Intraventricular haemorrhage grades $2-4$ & $24(12)$ & $6(8)$ & \\
\hline Respiratory distress syndrome & $144(69)$ & $54(69)$ & \\
\hline Septicaemia & $53(26)$ & $30(38)^{*}$ & \\
\hline Retinopathy of prematurity stage $3-5$ & $19(9)$ & $4(5)$ & \\
\hline Oxygen dependency at the age corresponding to $36 \mathrm{GW}$ & 81 (39) & $31(40)$ & \\
\hline $\begin{array}{l}\text { Values are number }(\%) \text { or mean (range). } \\
\text { * } p<0.05 \text { (subcohort } v \text { entire cohort). } \\
t p<0.05 \text { (subcohort } v \text { control group). } \\
\text { GW, Gestational weeks. }\end{array}$ & & & \\
\hline
\end{tabular}

Table 1 summarises background information on all surviving ELBW infants of the subcohort and the control group. The controls who participated did not differ from those who did not with regard to the variables listed in table 1 .

Infants with birth weight below -2 SD based on Finnish intrauterine growth charts were classified as small for gestational age. ${ }^{9}$ The estimation of gestational age was based on ultrasound examination before the end of 20 weeks ( $82 \%$ ) or on the last menstrual period ( $18 \%)$. The criterion for septicaemia was a positive blood culture. International criteria were used to grade respiratory distress syndrome, ${ }^{10}$ intraventricular haemorrhage, ${ }^{11}$ necrotising enterocolitis, ${ }^{12}$ and retinopathy of prematurity. ${ }^{13}$ The diagnostic criterion for blindness was based on the specification of $\mathrm{WHO}^{14}$ At the age corresponding to 36 weeks gestation, infants with muscular hypotonia or hypertonia or seizures were classified as neurologically abnormal.

\section{METHODS}

\section{National follow up schedule}

The national outcome data for ELBW infants were recorded from all five universities (the catchment areas of which were designated A-E for analysis and comparison) and 18 central or local hospitals up to the corrected age of $18 \pm 2$ months. A national neurological follow up programme included an ophthalmologic assessment at the corrected age of 12-18 months and examinations by a neurologist, psychologist, physiotherapist, and speech therapist ${ }^{15}$ at the corrected age of 18 months.

At the age of 18 months corrected for prematurity, cerebral palsy was defined as a non-progressive motor impairment with spastic or dystonic muscle tone, brisk tendon reflexes, positive Babinski's sign, and persistent primitive reflexes. Four

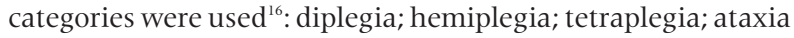
or athetosis syndrome. Other motor impairments were defined as delay in motor development, hypotonia or hypertonia with a specific cause (trisomy 21 , central nervous system malformation), or variable abnormalities in muscle tone without other features of cerebral palsy. The severity of the impairments was defined as follows: normal development (no impairments detected in the hearing, ophthalmological, motor, or speech assessment), mild impairment (one or two impairments detected in the above assessments, no blindness, hearing impairment, cerebral palsy, or convulsions), and severe impairment (three to four impairments in the above assessments or one of the following four impairments: blindness, hearing impairment, cerebral palsy, or convulsions).

The study population included $97 \%$ of all infants born before 27 weeks gestation, but of all infants born at 27 weeks gestation, the ELBW infants represented only $57 \%$, of those born at 28 weeks gestation $34 \%$, and of those born at 29 weeks gestation 16\%. Above 29 weeks gestation, the proportion of ELBW infants born at each gestational week was much less than $10 \%$. For this reason comparisons based on gestational age were made mainly in infants born at 26 weeks gestation or less, and thus included almost all infants per each gestational week. Comparisons based on birth weight were made at $100 \mathrm{~g}$ intervals.

\section{Regional programme}

In addition to the national follow up programme, two psychologists carried out developmental assessments on the subcohort and their controls at a corrected age of 24 months using the Bayley infant scale 2nd edition (mental section). ${ }^{17}$

\section{Statistical analysis}

Statistical analysis was performed using the SPSS program. Mantel-Haenzel, Pearson's $\chi^{2}$, and Fisher's exact tests were used to distinguish differences in binary or category variables and Student's $t$ test to distinguish differences in continuous variables. Logistic regression analysis was used to detect risk factors for cerebral palsy for any motor impairment. The perinatal and neonatal variables included in each logistic regression analysis were multiparity, pre-eclampsia, premature rupture of membranes, maternal infection, antenatal steroid treatment, hyperstimulation or in vitro fertilisation, maternal age below 20 or above 40 , smoking, marital status, social class $1-4,{ }^{18}$ birth in secondary level hospital, birth in the university hospital area A, B, C, D, or E, vaginal delivery, birth weight (100 g groups), intrauterine growth retardation, gestational age (full weeks), male, multiple birth, anomalies, 

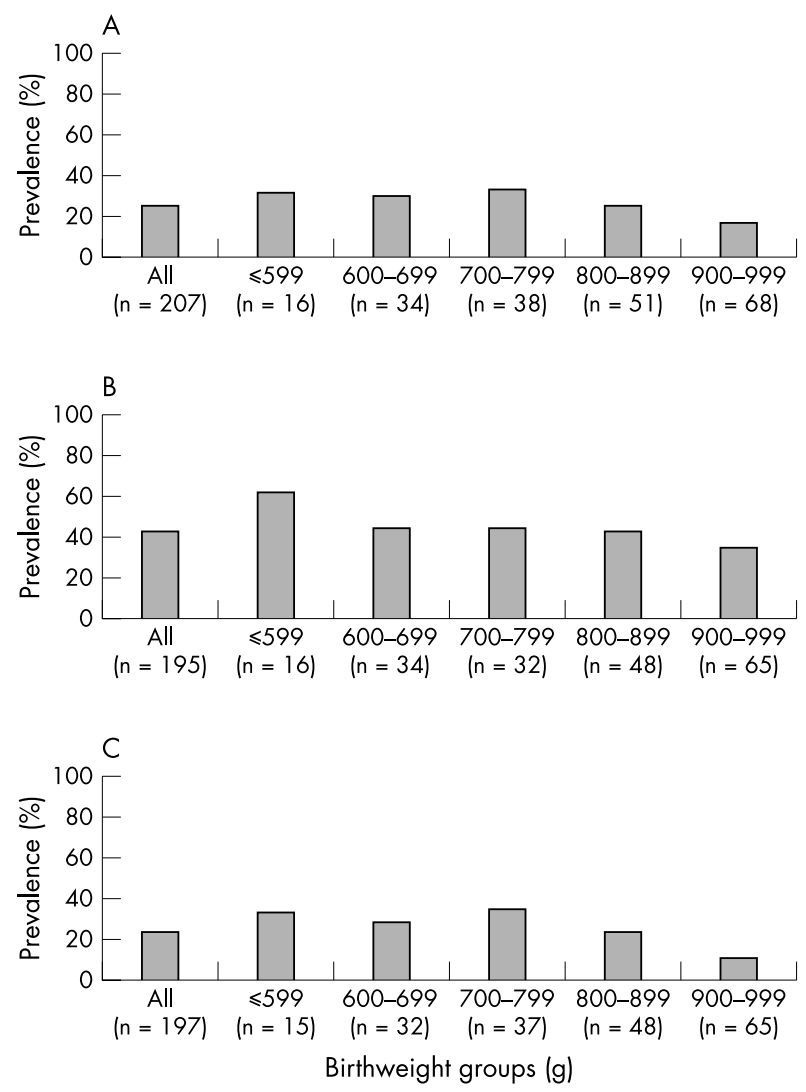

Figure 1 Prevalence of $(A)$ motor impairment, (B) delay in speech development, and $(C)$ abnormalities in ophthalmic assessment at the corrected age of 18 months in different birthweight groups.

respiratory distress syndrome, septicaemia, necrotising enterocolitis with perforation, and intraventricular haemorrhage grades 2-4. All variables were entered stepwise both forwards and backwards. A linear regression model was used to find risks for poor performance in Bayley assessment in the Helsinki ELBW subgroup and in their controls with the following variables included: prematurity, intrauterine growth retardation, sex, primiparity, vaginal delivery, multiple birth, mother's age, social class, smoking, marital status, examiner, day of birth - that is, number of days counted from 1 January 1996 to the birth to evaluate possible improvement over time-and the assessment age. In addition to the above factors, antenatal steroid treatment, maternal infection, pre-eclampsia, premature rupture of membranes, gestational age, birth weight, anomalies, respiratory distress syndrome, intraventricular haemorrhage grades $2-4$, necrotising enterocolitis with perforation, septicaemia, and examiner were included when the risks for poor scores in Bayley assessment were analysed in the ELBW infant subgroup. In linear regression analyses, variables were entered stepwise.

In all analyses, $\mathrm{p}<0.05$ was considered significant.

\section{Ethical consent}

The study was approved by the ethics committee of the Hospital for Children and Adolescents of Helsinki University Hospital and by the National Data Ombudsman.

\section{RESULTS}

The national cohort

Mortality

Of the 211 ELBW infants who survived until the age corresponding to 40 weeks gestation, three ( $1.4 \%)$ died before or at the corrected age of 24 months: one from chronic lung
Table 2 Prevalence of abnormalities in ophthalmic assessment, cerebral palsy, and all motor impairments (including cerebral palsy) at 18 months of corrected age in surviving extremely low birthweight infants born at 22-26 weeks gestation

\begin{tabular}{llll}
\hline $\begin{array}{l}\text { Gestational } \\
\text { age (weeks) }\end{array}$ & $\begin{array}{l}\text { Any abnormality } \\
\text { in ophthalmic } \\
\text { status }\end{array}$ & Cerebral palsy & $\begin{array}{l}\text { All motor } \\
\text { impairments }\end{array}$ \\
\hline $22-23$ & $3 / 4(75)$ & $1 / 5(20)$ & $1 / 5(20)$ \\
24 & $6 / 17(35)$ & $2 / 18(11)$ & $5 / 18(28)$ \\
25 & $10 / 32(31)$ & $4 / 34(12)$ & $9 / 33(27)$ \\
26 & $10 / 44(23)$ & $5 / 47(11)$ & $11 / 47(23)$ \\
\hline
\end{tabular}

Numbers of infants are given with percentages of those with data available in parentheses.

disease, one accidentally, and one multiply disabled infant from pneumonia. None was lost to follow up.

Ophthalmological examination at the age of 12 months Vision was assessed by a paediatrician, neurologist, or ophthalmologist on 197 (93\%) children at the corrected age of 12-18 months. Ophthalmic status was considered normal in $151(77 \%)$ children. The most common abnormality was strabismus $(\mathrm{n}=23,12 \%)$, myopia was found in $15(8 \%)$ and astigmatism, hyperopia, or retinal scars after treatment for retinopathy of prematurity in $10(5 \%)$ children. Two children had both strabismus and myopia. A total of $14(8 \%)$ children needed spectacles. One child was legally blind $(0.5 \%)$, and two ( $1 \%)$ had lost vision in one eye.

\section{Neurological outcome}

Neurological outcome was recorded in $90.3 \%$ of infants at 18 \pm 2 months of corrected age. In $4.4 \%$, the follow up examinations were performed at the corrected age of 12-15 months, and in $5.3 \%$ at the corrected age of 20-24 months.

Completely normal motor development was found in 157 $(76 \%)$ cases. The prevalence of cerebral palsy was 23/208 (11\%). Diplegia, the most common form of cerebral palsy, affected $15(7 \%)$, tetraplegia affected four $(2 \%)$, hemiplegia affected two $(1 \%)$, and ataxia or athetosis affected two $(1 \%)$ children. A total of 27 (13\%) children had motor impairment other than cerebral palsy: $16(8 \%)$ showed a delay in the normal age specific developmental milestones, three (1.5\%) had congenital anomaly affecting the central nervous system (trisomy 21 , meningomyelocele, or atrophy of cerebellum), and eight $(3 \%)$ children suffered from clumsiness, hypotonia, rigidity, or difficulty in controlling movement. A total of 3\% of all infants needed anticonvulsive treatment. Three children with otherwise normal motor development had congenital (two amnion strictures, one clubfoot) and one acquired (arterial thrombosis and amputation of one leg) anomaly affecting lower extremities. For analysis, they were included in the group of neurologically normal children.

In the verbal assessments, performed on 195 (94\%) children, mild developmental delay was found in 70 (36\%) cases and severe developmental delay in $12(6 \%)$ cases. Hearing was assessed by otoacoustic emission or brainstem auditory evoked potential measurement in $184(89 \%)$ infants: the hearing of 18 children was considered normal and the data for six children were missing. Six subjects suffered from hearing impairment necessitating hearing rehabilitation or the use of a hearing aid.

Figure 1 presents the prevalence of abnormalities in motor or verbal development and ophthalmic assessment in different birthweight groups. Table 2 shows motor impairment, cerebral palsy, and ophthalmic abnormality rates in infants born at 22-26 weeks gestation. In infants born after 26 weeks 


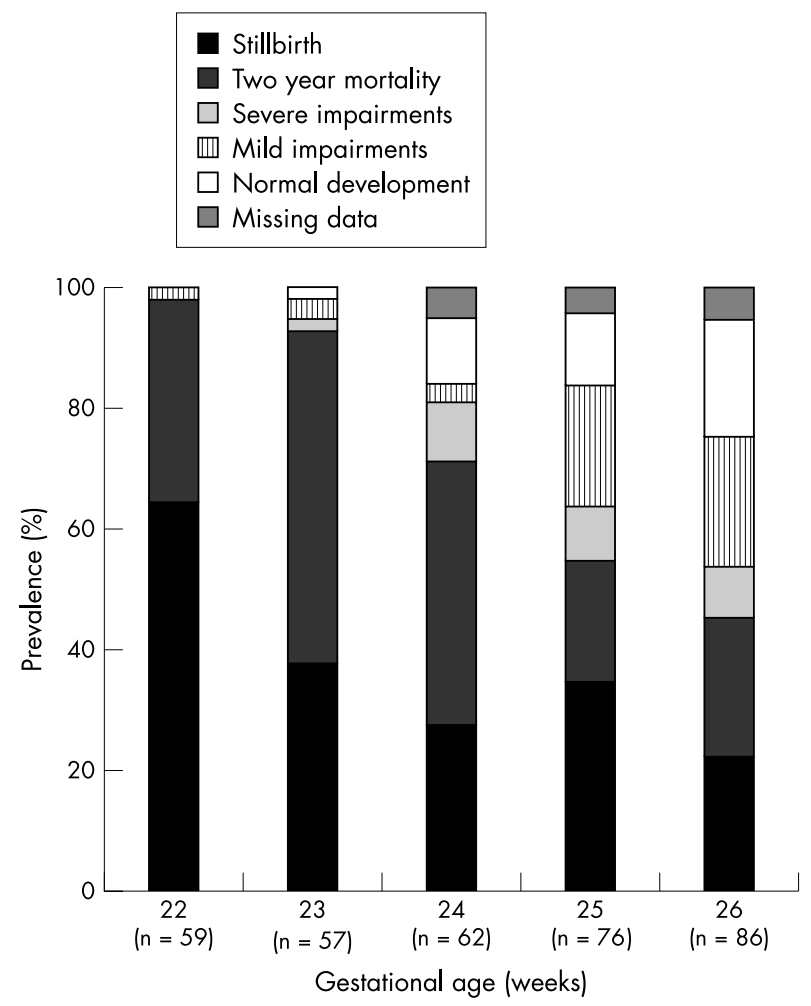

Figure 2 Stillbirth rate, two year mortality rate, prevalence of severe impairments, mild impairments, and normal development, and missing developmental data in extremely low birthweight infants born at 22-26 gestational weeks. Severe impairment was defined as cerebral palsy, blindness, hearing impairment necessitating hearing aid, seizures, or a combination of three or more milder impairments detected in the ophthalmic, hearing, motor, or speech assessment.

gestation, the prevalence of abnormalities in the vision assessment was $15 \%(16 / 105)$, cerebral palsy was found in $10 \%$, and any motor abnormality in $23 \%$. No infant born at 27 weeks gestation or more was blind or had hearing impairment necessitating a hearing aid.

\section{Overall outcome}

Complete data on hearing disability necessitating a hearing aid, verbal, motor, and ophthalmic impairments were available for $186(88 \%)$ children. Figure 2 shows data on mortality and severity of impairments in infants born at 22-26 weeks gestation.

\section{Risk factors}

A significant decrease in ophthalmic abnormalities was found in all surviving infants with increasing birth weight $(\mathrm{p}=0.010)$, and in infants born at 22-26 weeks gestation with increasing gestational age $(p=0.040)$. However, no significant differences in prevalence of cerebral palsy, any motor impairment, verbal impairment, or hearing impairment necessitating a hearing aid were found between the birthweight groups or between the gestational age groups 22-26 weeks. Intrauterine growth retardation or birth outside of a tertiary care centre did not seem to be risks for any of these impairments in surviving ELBW infants.

Table 3 lists significant risk factors found in logistic regression analysis for cerebral palsy or for any motor impairment in surviving infants, and for motor impairment or death in liveborn infants.

The second logistic regression analysis included outcome measures at the age corresponding to 36 weeks gestation (retinopathy of prematurity, neurological status, or need for extra oxygen) as explanatory factors. An abnormal neurological status (hypotonia or hypertonia, or seizures) at the age corresponding to 36 weeks gestation was a risk for cerebral palsy (odds ratio $(\mathrm{OR})=4.3, \mathrm{p}=0.005$ ) and for overall motor impairment ( $\mathrm{OR}=4.3, \mathrm{p}=0.002)$. Oxygen dependency was a risk factor for motor impairment $(\mathrm{OR}=2.1, \mathrm{p}=0.038)$ and for ophthalmic problems $(\mathrm{OR}=2.6, \mathrm{p}=0.014)$, whereas retinopathy of prematurity grade 3-5 was a risk for ophthalmic abnormalities $(\mathrm{OR}=16.5, \mathrm{p}<0.001)$ in the surviving children.

\section{The regional subcohort}

Four infants were excluded from the Bayley infant scale mental assessment, performed on the subcohort at a mean age of 2.0 years (range 1.84-2.26); the assessment of two children was impossible because of a combination of language, social, and developmental problems. Two otherwise normal children were not examined because of exhaustion after other assessments during the same day or because the parents withdrew them from the study. One ELBW child did not pass the test because of severe mental retardation. All participating controls were assessed at the mean age of 2.2 years (range 1.91-2.73).

The ELBW children had significantly lower mean (SD) Bayley mental scores than controls (95.1 (12.9) v 106.3 (9.6); $\mathrm{p}<0.001)$. Seventeen ELBW infants $(22 \%)$ had Bayley scores below 85 , and one ( $1 \%$ ) below 70 . One of the control infants had Bayley scores below 85 .

In a linear regression analysis comparing ELBW infants with controls, prematurity decreased the Bayley mental score by 10.4 points $(\mathrm{SE}=1.8, \mathrm{p}<0.001)$ and male sex by 5.6 points ( $\mathrm{SE}=1.8, \mathrm{p}=0.002$ ); the scores seem to improve by 0.013 point per birth day (counted from 1 January 1996) during the two year study period $(\mathrm{SE}=0.004 ; \mathrm{p}=0.004)$. When the ELBW infants and the control group were analysed separately, the only significant factor for the ELBW infants was the number of days counted from 1 January 1996 to the birth; the scores seem to improve 0.024 point per day $(\mathrm{SE}=0.007$, $\mathrm{p}=0.001)$. In the control group, no such improvement over time was found, and the only significant risk factor for poor outcome in linear regression analysis was male sex, which seemed to reduce the scores by 6.3 points ( $\mathrm{SE}=2.133$, $\mathrm{p}=0.005$ ).

The correlation between Bayley scores and the day of birth was $0.388(p=0.001)$ in the ELBW infant group. No such correlation was found in the control group $(r=0.072$; $\mathrm{p}=0.537)$.

\section{DISCUSSION}

By establishing a national ELBW infant research register with detailed background and follow up information, we could satisfactorily evaluate outcome in the study cohort at 18 months of age. Although 23 hospitals participated in the prospective data collection, $75 \%$ of the data came from the five university clinics responsible for the study design. However, using data gathered from the national healthcare system caused some limitations-for example, the neurological assessments were performed by several clinicians. The possible bias resulting from many investigators may have been avoided by performing a centralised study, but this kind of study does not usually extend to all inclusive follow up rate. In our study, no infant was lost to follow up, but the data were nevertheless not fully comprehensive. The classification of impairment severity used only those with complete data available and may be somewhat overstated because it seems that missing data mostly resulted from the practice not to perform some assessments on children with apparently normal development.

Mortality in ELBW children during the first two years after discharge was comparable to that in other studies ${ }^{19} 20$; however, none of the infants in our study population died from sudden infant death syndrome, for which prematurity is thought to be a risk factor. 
Table 3 Significant risk factors for cerebral palsy any motor impairment in surviving infants and for death or the motor impairments in liveborn infants expressed as the odds ratios (OR), p values, and $95 \%$ confidence intervals $(95 \% \mathrm{Cl})$

\begin{tabular}{|c|c|c|c|c|c|c|}
\hline & \multicolumn{3}{|c|}{ Cerebral palsy } & \multicolumn{3}{|c|}{$\begin{array}{l}\text { Death before the corrected age of } 2 \text { years or } \\
\text { cerebral palsy }\end{array}$} \\
\hline & OR & $95 \% \mathrm{Cl}$ & $\mathrm{p}$ Value & OR & $95 \% \mathrm{Cl}$ & $\mathrm{p}$ Value \\
\hline No antenatal steroid treatment & 3.6 & 1.3 to 10.0 & 0.015 & 3.2 & 1.7 to 5.9 & $<0.001$ \\
\hline Vaginal delivery & 4.3 & 1.5 to 12.2 & 0.006 & 2.7 & 1.4 to 5.2 & 0.003 \\
\hline Birth in the university hospital area $C$ & 0.1 & 0.02 to 0.4 & 0.003 & 0.3 & 0.2 to 0.6 & $<0.001$ \\
\hline Birth in the university hospital area $\mathrm{A}$ & 0.2 & 0.03 to 0.8 & 0.030 & - & & \\
\hline Birth weight (per $100 \mathrm{~g}$ increase) & - & & & 0.7 & 0.6 to 0.9 & 0.004 \\
\hline Gestational age (per one week increase) & - & & & 0.8 & 0.7 to 0.997 & 0.046 \\
\hline Anomalies & - & & & 3.6 & 1.2 to 10.8 & 0.021 \\
\hline \multirow{3}{*}{ Intraventricular haemorrhage grade $2-4$} & - & & & 2.5 & 1.2 to 5.3 & 0.017 \\
\hline & \multicolumn{3}{|c|}{ Any motor impairment } & \multicolumn{3}{|c|}{$\begin{array}{l}\text { Death before the corrected age of } 2 \text { years or } \\
\text { any motor impairment }\end{array}$} \\
\hline & OR $(p)$ & $95 \% \mathrm{Cl}$ & $\mathrm{p}$ Value & OR $(p)$ & $95 \% \mathrm{Cl}$ & $\mathrm{p}$ Value \\
\hline No antenatal steroid treatment & 3.6 & 1.6 to 8.1 & 0.001 & 3.3 & 1.7 to 6.2 & 0.002 \\
\hline Maternal infection & 0.3 & 0.1 to 0.7 & 0.005 & 0.5 & 0.3 to 0.95 & 0.034 \\
\hline Male & 2.9 & 1.3 to 6.2 & 0.006 & 2.1 & 1.2 to 3.6 & 0.010 \\
\hline Intaventricular haemorrhage grade 2-4 & 3.1 & 1.0 to 9.2 & 0.042 & 2.5 & 1.1 to 5.3 & 0.022 \\
\hline Birth in university hospital area $C$ & - & & & 0.4 & 0.3 to 0.8 & 0.005 \\
\hline Vaginal delivery & _ & & & 2.9 & 1.5 to 5.3 & 0.001 \\
\hline Birth weight (per $100 \mathrm{~g}$ increase) & _ & & & 0.6 & 0.5 to 0.7 & $<0.001$ \\
\hline
\end{tabular}

Ophthalmic problems are relatively common in ELBW children. Compared with most previous studies, in which visual impairment rates varied between $6 \%$ and $9 \%,{ }^{20}{ }^{21}$ ophthalmic abnormalities in our study were more common $(23 \%)$. The difference may be partly explained by the fact that we included even mild cases without visual impairment or need for treatment. However, similar high rates of ocular abnormalities were found in the study of Pennefather et al. ${ }^{22}$ The prevalence of blindness was comparable to numerous follow up studies $(0.5-3.6 \%),{ }^{120-25}$ and our study also confirms the finding of Emsley et $a^{26}$ that infants born extremely prematurely are at particular risk of visual disabilities.

The prevalence of cerebral palsy in the whole country is comparable to recent results from Sweden, the United States, Australia, and Canada, where the detected prevalence of cerebral palsy at the age of $1-3$ years varied between $7 \%$ and $17 \%$. ${ }^{2023242728}$ When the results of the subcohort of our study were compared with those of an earlier regional cohort born in 1991-1994 in the same area, neonatal mortality seemed to have decreased from $31 \%$ to $21 \%(p=0.046)$ and the prevalence of cerebral palsy from $17 \%$ to $4 \%(p=0.002){ }^{29}$ Thus, despite the increased survival rate of ELBW infants, the prevalence of cerebral palsy did not increase in the region. In logistic regression analysis, detected differences in mortality and cerebral palsy prevalence also indicate that decreased mortality is not always associated with increased morbidity. As previously reported, ${ }^{30}$ this study showed that regional differences occur in mortality and morbidity even in a country with a homogeneous population and social security and that both morbidity and mortality should be included when quality of care is analysed to avoid the effect of selection by outcome.

Kitchen et $a l^{31}$ suggested that neurological findings at 2 years of age are too pessimistic, and that $33 \%$ of children had a poorer diagnosis at that age than at 5 , and in only $4 \%$ was the outcome at 2 years of age better than at 5 . However, in comparison with normal weight children, Halsey et $a l^{32}$ has shown that ELBW children classified as non-disabled at an early age show a significantly poorer performance on cognitive, verbal, perceptual, motor, and visual-motor measures at preschool age, a finding also supported by Saigal et al..$^{33}$ The rate of normal development in our study (42\%) was lower than that found in some previous studies, ${ }^{19-2128} 3435$ but we also recorded minor, non-disabling impairments. The prognostic value of these minor impairments in later develop- ment is an important subject for subsequent studies, for which a uniform classification of disabilities, such as the recently published Health Status Questionnaire, ${ }^{36}$ would provide even more generalisable results.

The effect of gestational age on neurological development in ELBW infants is contradictory. Several investigators have found no independent effect of gestational age on later outcome, ${ }^{353738}$ whereas others report an effect. ${ }^{163940}$ In our study population, which included virtually all infants born in Finland at 26 weeks gestation, gestational age was not an independent risk factor for later impairments (cerebral palsy, motor and hearing impairments, speech delays), not even in a multivariate logistic regression analysis. Abnormal ophthalmological status was more common in children born extremely prematurely, at the limit of viability 22-24 weeks. In a previous study, we found gestational age and birth weight to be significant risks for death. ${ }^{8}$ Thus, we assume that the majority of the most immature infants died, and the infants who survived had as favourable a prognosis as the more mature ones in all other domains except visual acuity.

Poorer cognitive skills in ELBW children compared with full term controls has been a universal finding. ${ }^{32}{ }^{33} 41-43$ The ELBW infants in our study population differed from their controls in that their mothers were more likely to belong to a lower social class. Although a lack of maternal education and low social class have been shown to be risk factors for poor cognitive development of premature children, ${ }^{12035373941}$ in our study population deficient maternal education was not a risk factor for poor outcome.

The effect of the date of birth on Bayley scores of ELBW children was an unexpected finding. The same two well trained investigators examined the ELBW and control children. No such correlation was found in the controls, confirming the reliability of the method. Neither could the result be explained by selection by outcome, because neonatal mortality in ELBW infants did not change during the study period. It may be that the outcome improved because of improved perinatal and neonatal care. Which factors were improved and whether the improvement is permanent remains to be seen.

In conclusion, at the corrected age of 18 months, no outcome differences were detected between birthweight groups or in ELBW infants born at 22-26 weeks gestation in sensory-motor outcome except for ophthalmic abnormalities, the rate of which declined significantly with increasing birth weight and gestational age. In the Helsinki University Hospital, the scores from the Bayley mental test seemed to improve 
during the short study period, but this needs to be confirmed. Our results also show that, even in a country with a uniform healthcare system, some regional differences in early neurological outcome of ELBW children exist, which warrants continuous quality control and audit. Major disabilities-that is, cerebral palsy, blindness, deafness, and mental retardationare usually discovered at the age of 2 years. However, follow up should be continued to at least preschool age to detect cognitive disabilities such as problems in learning, behaviour, and attention.

\section{ACKNOWLEDGEMENTS}

This study was supported by grants from the Finnish Paediatric Foundation and Signe and Ane Gyllenberg Foundation.

\section{Authors' affiliations}

V Tommiska, A-L Järvenpää, T Salokorpi, V Fellman, Hospital for Children and Adolescents, University of Helsinki, Helsinki, Finland K Heinonen, Department of Paediatrics, University of Kuopio, Kuopio, Finland

P Kero, Department of Paediatrics, University of Turku, Turku, Finland M-L Pokela, Department of Paediatrics, University of Oulu, Oulu, Finland O Tammela, Department of Paediatrics, University of Tampere, Tampere, Finland

M Virtanen, The National Research and Development Centre for Welfare and Health, Helsinki

\section{REFERENCES}

1 O' Shea TM, Klinepeter KL, Goldstein DJ, et al. Survival and developmental disability in infants with birth weights of 501 to 800 grams, born between 1979 and 1994. Pediatrics 1997;100:982-6.

2 La Pine TP, Jackson JC, Bennet FC. Outcome of infants weighing less than 800 grams at birth: 15 years' experience. Pediatrics 1995:96:479-83.

3 French NP, Parry TS, Evans S. Improving outcome for Western Australian infants with birthweights 500-999 g. Med J Aust 1995; 162:295-9.

4 Blaymore-Bier J, Pezullo J, Kim E, et al. Outcome of extremely low-birth-weight infants: 1980-1990. Acta Paediatr 1994;83:1244-8.

5 Wood NS, Marlow N, Costeloe K, et al. Neurologic and developmental disability after extremely preterm birth. EPICure Study Group. N Engl J Med 2000;343:378-84

6 Piecuch RE, Leonard $\mathrm{CH}$, Cooper BA, et al. Outcome of infants born at 24-26 weeks' gestation: II. Neurodevelopmental outcome. Obstet Gynecol 1997;90:809-14.

7 Tin W, Fritz S, Wariyar U, et al. Outcome of very preterm birth. Children reviewed with ease at 2 years differ from those followed up with difficulty. Arch Dis Child Fetal Neonatal Ed. 1998:79:F83-7.

8 Tommiska V, Heinonen K, lkonen S, et al. A national short-term follow-up study of extremely low birth weight infants born in Finland in 1996-1997. Pediatrics 2001;107:e2.

9 Pihkala J, Hakala T, Voutilainen P, et al. [Characteristic of recent feta growth curves in Finland]. Duodecim 1989:105:1540-6.

10 Rudolph AJ, Smith CA. Idiopathic respiratory distress syndrome in newborn. J Pediatr 1960;57:905-21

11 Papile LA, Burstein J, Burstein R, et al. Incidence and evolution of subependymal and intraventricular hemorrhage: a study of infants with birth weights less than 1,500 gm. J Pediatr 1978;92:529-34.

12 Bell MJ, Ternberg JL, Feigin RD, et al. Neonatal necrotizing enterocolitis. Therapeutic decisions based upon clinical staging. Ann Surg 1978;187:1-7.

13 The Committee for the Classification of Retinopathy of Prematurity. An international classification of retinopathy of prematurity. Arch Ophthalmol 1984;102:1130-4.

14 Steinkuller PG, Du L, Gilbert C, et al. Childhood blindness. Journal of the American Association for Pediatric Ophthalmology and Strabismus 1999;3:26-32.

15 Reynell J. Manual for the developmental language scales (revised) Windsor: NFER-Nelson Publishing, 1978

16 Hagberg B, Hagberg G, Olow I, et al. The changing panorama of cerebral palsy in Sweden. VII. Prevalence and origin in the birth year period 1987-1990. Acta Paediatr 1996:85:954-60.

17 Bayley N. Bayley scales of infant development. 2nd ed. San Antonio, TX: Psychological Corporation, 1993

18 Gissler M, Rahkonen O, Jarvelin MR, et al. Social class differences in health until the age of seven years among the Finnish 1987 birth cohort Soc Sci Med 1998:46:1543-52.

19 Dezoete A, MacArthur BA, Aftimos S. Developmental outcome at 18 months of children less than 1000 grams. NZ Med J 1997;1 10:205-7.

20 Vohr BR, Wright LL, Dusick AM, et al. Neurodevelopmental and functional outcomes of extremely low birth weight infants in the Nationa Institute of Child Heath and Human Development Neonatal Research Network, 1993-1994. Pediatrics 2000;105:1216-26.
21 Cooke RWI. Factors affecting survival and outcome at 3 years in extremely preterm infants. Arch Dis Child 1994;71:F28-31.

22 Pennefather PM, Clarke MP, Strong NP, et al. Ocular outcome in children born before 32 weeks gestation. Eye 1995;9:26-30.

23 Hack M, Friedman H, Fanaroff A. Outcomes of extremely low birth weight infants. Pediatrics 1996:98:931-7.

24 Robertson CMT, Sauve RS, Christianson HE. Province-based study of neurologic disability among survivors weighing 500 through 1249 grams at birth. Pediatrics 1994;93:636-40.

25 Lefebvre F, Glorieux J, St-Laurent-Gagnon T. Neonatal survival and disability rate at age 18 months for infants born between 23 and 28 weeks of gestation. Am J Obstet Gynecol 1996;174:833-8.

26 Emsley HC, Wardle SP, Sims DG, et al. Increased survival and deteriorating developmental outcome in 23 to 25 week old gestation infants, 1990-1994 compared with 1984-9. Arch Dis Child 1998:78:F99-104.

27 Finnström O, Otterblad Olausson P, Sedin G, et al. Neurosensory outcome and growth at three years in extremely low birth weight infants: follow-up results from Swedish national prospective study. Acta Paediatr 1998:87:1055-60.

28 The Victorian Infant Collaborative Study Group. Improved outcome into the 1990s for infants weighing 500-999 g at birth. Arch Dis Child Fetal Neonatal Ed 1997;77:F91-4

29 Salokorpi T, Rajantie I, Viitala J, et al. Does perinatal hypocarbia play a role in the pathogenesis of cerebral palsy? Acta Paediatr 1999;88:1-5.

30 Finnström O, Otterblad Olausson P, Sedin G, et al. The Swedish national prospective study on extremely low birthweight (ELBW) infants Incidence, mortality and survival in relation to level of care. Acta Paediatr 1997:86:503-11.

31 Kitchen W, Ford G, Orgill A, et al. Outcome in infants of birth weight 500 to $999 \mathrm{~g}$ : a continuing regional study of 5 -year-old survivors. J Pediatr 1987;111:761-6.

32 Halsey CL, Collin MF, Anderson CL. Extremely low birth weight children and their peers: a comparison of preschool performance. Pediatrics 1993:91:807-11.

33 Saigal S, Hoult LA, Streiner DL, et al. School difficulties at adolescence in a regional cohort of children who were extremely low birth weight. Pediatrics 2000; 105:325-31.

34 Stjernquist K, Svenningsen NW. Extremely low birth weight infants less than $901 \mathrm{~g}$. Growth and development after one year of life. Acta Paediatr 1993;82;40-2.

35 Piecuch RE, Leonard CH, Cooper BA, et al. Outcome of extremely low birth weight infants (500 to 999 grams) over a 12-year period. Pediatrics 1997; 100:633-9.

36 Jones HP, Guildea ZE, Stewart JH, et al. The Health Status Questionnaire: achieving concordance with published disability criteria. Arch Dis Child 2002;86:15-20.

37 Hille E, Ouden LD, Baver L, et al. School performance at nine years of age in very premature and very low birth weight infants: prenatal risk factors and predictors at five years of age. J Pediatr 1994:125:426-34.

38 Doyle LW for the Victorian Infant Collaborative Study Group. Outcome to five years of age of children born at 24-26 week' gestational age in Victoria. Med J Aust 1995;163:11-14.

39 Koller H, Lawson K, Rose SA, et al. Patterns of cognitive development in very low birth weight children during the first six years of life. Pediatrics 1997;99:383-9.

40 Johnson A, Townshend P, Yudkin P, et al. Functional abilities at the age of 4 years of children born before 29 weeks of gestation. BM 1993;306:1715-18.

41 Klebanov PK, Brooks-Gunn J, McCormick MC. Classroom behavior of very low birth weight elementary school children. Pediatrics 1994;94:700-8

42 Bylund B, Cervin T, Finnström O, et al. Morbidity and neurological function of very low birth weight infants from the newborn period to $4 \mathrm{y}$ of age. A prospective study from the south-east region of Sweden. Acta Paediatr 1998;87:758-63.

43 Hack M, Taylor HG, Klein G, et al. Schoolage outcomes in children with birth weights under $750 \mathrm{~g}$. N Engl J Med 1994;331:753-9.

\section{COMMENTARY}

\section{POPULATION BASED OUTCOMES FOR HIGH RISK NEWBORN INFANTS}

This edition of Fetal and Neonatal includes three reports which have evaluated a variety of high risk national populations over time, by clinical group, and with two year outcomes respectively. The collection of national data is valuable because of the possibility of comparing the outlook for children born within health systems, rather than within enthusiastic centres. The reports come from the established and ongoing Australia and New Zealand Neonatal Network (ANZNN) and from a Finnish national survey. Criteria for inclusion differ between these and other registries but most can agree that those $<1001 \mathrm{~g}$ birth weight or the extremely preterm are those at highest risk and should be included 
The two reports from the ANZNN are valuable because they describe a broad population of infants, intending to be inclusive and registering babies who are ventilated after birth or receive "major" neonatal surgical operations, in addition to conventional $<1500$ g or $<32$ weeks gestation groupings. In the main paper describing the outcome for the preterm, ventilated, and surgical groups, the data give a fascinating insight into the working of the New Zealand health system for newborn infants and demonstrate that excellent outcomes can be achieved. These data form the basis for future comparisons, which we undoubtedly will see. The comprehensive data collection process represent a major success for the providers (the neonatal teams in the two countries) and the commissioners (the health authorities) who have unrivalled information on what is happening to a small but relatively expensive sector of their health economy.

The second paper from the New Zealand group shows us what can be achieved by comparing health status over time within a population. Thankfully it provides no major surprises and major reassurance that things appear to be improving. The report demonstrates the increasing concentration of care within the level III neonatal intensive care units in New Zealand, with a halving of the proportion of babies delivered at level I or level II hospitals. The report highlights the $7 \%$ of infants who are failing to receive appropriate screening for retinopathy of prematurity. Here is a target group where health care can easily be improved and monitored. In the UK, there is an ongoing national audit of outcomes and screening following publication of guidelines and a series of "Retinopathy Roadshows", to encourage awareness and the importance of recognition of this eminently treatable condition. The lack national data on such outcomes or central collation of the effectiveness of individual hospital's through the recommended system of annual reports ${ }^{1}$ means that this important statistic cannot be measured or monitored without difficult and time-consuming focussed audits.

The report from Finland describes the outcome at 18 months to two years in a national cohort of extremely low birthweight babies. This represents a huge effort and coordination to achieve a multidisciplinary assessment at 18 months on a geographically dispersed population. There is a very high frequency of impairment among survivors although the severity of disability is not really very clear: children with cerebral palsy and hearing impairment requiring amplification have major impairments, but their degree of disability will vary widely. Depending on the outcomes you are interested in it is important to separate out the impairments, which can be used to evaluate perinatal influences and predictors, and disability which defines the health status of the population and may be of more value to professionals and parents in clinical practice. ${ }^{2}$ It is interesting to compare the relative survival of babies < 1001g birthweight in Finland (1996-7)—62\% live births and New Zealand (1998-9)—80\% live births. These striking differences are not assessable in the absence of comparable disability data, as they may simply reflect different approaches to borderline viability. ${ }^{3}$

How applicable are these efforts to current UK practice? The birth population of New Zealand is marginally less than that of the NHS Trent Region (50-60 000 births per annum). The Trent Neonatal Survey has managed to collect information on a consistent basis since 1986 in a similar vein to that of the ANZNN, but does not attempt to collect standardised outcome data as the increase in resources required is massive. Some other geographic areas have similar ongoing work. Nonetheless to extend the Trent Survey to the whole UK would be a serious undertaking, but not impossible as shown by the success of the Vermont Oxford Network.

One important goal for neonatology must be to properly determine what is the current outcome for key groups and to produce comparative data. The UK is currently inching towards nationally relevant data collation, ${ }^{4}$ an important initiative which the move to managed clinical networks for Neonatal Intensive Care will surely help to drive. We have a recommended dataset ${ }^{1}$ and definitions of disability ${ }^{5}$ which have been arrived at by consensus. We need to be clear about denominator data collection and start working together, because without information the debate as to the optimum configuration of care cannot ever be satisfactorily concluded.

N Marlow

Academic Division of Child Health, Queen's Medical Centre, Nottingham NG7 2UH, UK; neil.marlow@nottingham.ac.uk

\section{REFERENCES}

1 Anon. The BAPM Neonatal Dataset. London: BAPM, 1996 www.bapm-london.org

2 Johnson A. Disability and Perinatal Care. Pediatrics 1995:95:272-4.

3 Lorenz JM, Paneth N, Jetton JR, et al. Comparison of management strategies for extreme prematurity in New Jersey and the Netherlands: outcomes and resource expenditure. Pediatrics 2001;108:1269-74.

4 www.neonatal.net

5 Report of two working groups. Disability and perinatal care: Measurement of health status at two years. National Perinatal Epidemiology Unit and Oxford Health Authority, 1995. 